\title{
URDIDURA DAS DIRETRIZES CURRICULARES NACIONAIS DE PEDAGOGIA, O PROJETO PEDAGÓGICO E O CURRÍCULO: À LUZ DA COMPLEXIDADE NOS OPERADORES COGNITIVOS
}

\author{
ENTWINING THE NATIONAL CURRICULAR DIRECTIVES IN PEDAGOGY, THE \\ PEDAGOGIC PROJECT AND THE CURRICULUM IN THE LIGHT OF THE \\ COMPLEXITY OF THE COGNITIVE OPERATORS
}

\author{
URDIDURA DE LAS DIRECTRICES CURRICULARES NACIONALES DE PEDAGOGÍA, \\ EL PROYECTO PEDAGÓGICO Y EL CURRÍCULO: A LA LUZ DE LA COMPLEJIDAD EN \\ LOS OPERADORES COGNITIVOS
}

Clayton Marcelo Barone

E-mail: claytonesp@gmail.com

Celia Maria Hass

E-mail: celia.haas@unicid.edu.br

Universidade Cidade de São Paulo - UNICID

\begin{abstract}
RESUMO
O presente artigo tem por objetivo analisar as Diretrizes Curriculares Nacionais do Curso de Pedagogia Resolução n. ${ }^{\circ} 1$ do CNE/CP, de 15 de maio de 2006, à luz do Pensamento Complexo de Edgar Morin. É um estudo de natureza qualitativa, de caráter exploratório; os procedimentos metodológicos utilizados foram a análise documental no que se refere à legislação que disciplina o curso de Pedagogia. Suas DCNs orientam as Instituições de Educação Superior (IES) a organizar a respectiva matriz curricular no âmbito da formação do futuro pedagogo, mas apresentam lacunas entre o alcançável e o desejável, razão por quê se preferiu a leitura pela ótica do Pensamento Complexo de Edgar Morin. Discutiu-se igualmente o projeto pedagógico e seu papel na relação com as DCNs do curso de Pedagogia à luz dos operadores cognitivos do Pensamento Complexo. A pesquisa contou com o amparo teórico de Morin (2008, 2010, 2011, 2015), Moraes (2015), Petraglia (2010, 2013), Mariotti (2000, 2010), Veiga (2004, 2012) e Sacristán (2000), entre outros. As análises das relações estabelecidas à luz do Pensamento Complexo permitiram compreender as ações e intervenções simultâneas, que são todos os fios da trama, costurados e urdidos com as DCNs ao longo da formação dos futuros pedagogos.
\end{abstract}

PALAVRAS-CHAVE: Diretrizes Curriculares Nacionais. Teoria de currículo. Projeto pedagógico. Pensamento Complexo. Operadores Cognitivos.

\section{ABSTRACT}

The purpose of this study is to analyse the National Curricular Directives for the course of Pedagogy Resolution 1 at CNP/CP, of May 15,2006 - in the light of Edgar Morin's complex thought. The research has a qualitative nature and an exploratory character, the methodological procedures being the documental analysis concerning the legislation that outlines the course of Pedagogy. The NCDs guide the Institutions of Higher Education (IES) to shape their curricular matrix in view of the formation of future pedagogues, despite the inevitable gap between what is expected and what is attainable, which suggested the reading through the viewpoint of Edgar Morin's complex thought. The Pedagogic Project and its role in mingling the NCDs in the framework and the environment of the course of Pedagogy was a permanent concern of reflection inspired by cognitive operators of complex thought. A wide array of scholars was referred, starting with the theoretical support of Morin (2008, 2010, 2011, 2015), but also Moraes (2015), Petraglia (2010, 2013), Mariotti (2000, 2010), Veiga (2004, 2012) and Sacristán (2000), among others.The analyses of the rapports elicited by Morin's complex thought made it possible to understand the simultaneous actions and reactions - the threads in the weaving, sewn and warped with NCDs in the stride of future pedagogues' formation.

KEY-WORDS: National Curricular Directives. Curriculum theory. Pedagogical project. Complex Thought. Cognitive operators. 


\section{RESUMEN}

El presente articulo tiene por objetivo analizar las Directrices Curriculares, Nacionales del Curso de Pedagogía - Resolución $N^{o} 1$ del CNE / CP, de 15 de mayo de 2006, a la luz del Pensamiento Complejo de Edgar Morin. La investigación es un estudio de naturaleza cualitativa y de carácter exploratorio; los procedimientos metodológicos utilizados fueron el análisis documental en lo que se refiere a la legislación que disciplina el Curso de Pedagogía. Las DCNs del curso de Pedagogía orientan a las Instituciones de Educación Superior - IES a organizar su matriz curricular en el ámbito de la formación del futuro pedagogo, pero presentan huecos entre lo alcanzable y lo deseable, razón por la que se prefirió la lectura por la óptica del Pensamiento Complejo Edgar Morin. Se discutió igualmente el proyecto pedagógico y su papel en la relación con las DCNs del curso de Pedagogía a la luz de los operadores cognitivos del Pensamiento Complejo. La encuesta contó con el amparo teórico de Morin (2008, 2010, 2011, 2015), Moraes (2015), Petraglia (2010, 2013), Mariotti (2000, 2010), Veiga (2004, 2012) y Sacristán (2000), entre otros. Los análisis de las relaciones que establecemos a la luz del Pensamiento Complejo he permitido comprender las acciones e intervenciones simultáneas, que son todos los hilos de la trama, cosidos y urdidos con las DCNs a lo largo de la formación de los futuros pedagogos.

PALABRAS-CLAVE: Directrices Curriculares Nacionales. Teoría de currículum. Proyecto pedagógico. Pensamiento complejo. Operadores cognitivos.

\section{INTRODUÇÃO}

Este artigo apresenta os resultados da pesquisa Tessituras, urdiduras e lançadeiras do curso de Pedagogia: leituras das diretrizes curriculares nacionais e as interpretações dos professores universitários à luz do pensamento complexo (BARONE, 2017) com interesse particular nas relações entre as $\mathrm{DCNs}^{\mathrm{i}}$ do Curso de Pedagogia e o Projeto Pedagógico, analisados em uma perspectiva do Pensamento Complexo de Edgar Morin. Porém, o que vem a ser urdidura? É o "1. Ato ou efeito de urdir. 2. Os conjuntos de fios dispostos no tear, e por entre os quais passam os fios da trama" (FERREIRA, 2008, p. 802). Metaforicamente, estabeleceu-se que os fios da urdidura são as Diretrizes Curriculares Nacionais (DCNs) do curso de Pedagogia, as quais - permitindo que o curso universitário se desenvolva e estruture - são cotidianamente tecidas pela ação de professores e alunos, muitas vezes em resposta às políticas públicas instituídas.

Assim, o presente artigo reflete as DCNs e o papel do currículo na educação superior, em uma nova ótica, objetivando compreender as relações de totalidade destes documentos de forma globalizada, sem fragmentação, a partir das possibilidades que oferecem os operadores cognitivos da complexidade de Morin.

\subsection{Trama dos Operadores Cognitivos do Pensamento Complexo}

A complexidade é a trama tecida em conjunto das entrelinhas da existência humana. Interpreta-se complexidade não como complicação, mas no seu sentido de trama, teia que 
envolve as reações e interações da vida. O pensamento complexo é a própria vida, muito mais concreto que uma simples teoria, já que é parte essencial do cotidiano, desafio diário de contradições e interações variadas que o mundo natural nos apresenta. Para Morin (2011a), existem três princípios que auxiliam a pensar a complexidade: dialógico, recursivo e hologramático. Esses princípios-guia ajudam a compreender a complexidade e colocá-la em prática.

O primeiro princípio - dialógico ${ }^{\mathrm{ii}}$ - envolve e entrelaça determinadas situações que, em um primeiro momento, apresentam-se separadas, tais como o real e o imaginário, a ciência e a arte, razão e emoção e a razão e os mitos. Assim, estes pensamentos são complementares e antagônicos, já que "não sendo simplesmente justapostos, eles são necessários um ao outro" (MORIN, 2011a, p. 73). Segundo Morin, o dialógico “é a associação complementar dos antagonismos que nos permite religar ideias que se rejeitam mutuamente, como a ideia de vida e de morte" (MORIN, 2010, p. 114). Assim, do mesmo modo que o oxigênio permite o desenvolvimento da vida, simultaneamente ele gera o processo de oxidação, logo a morte, que, em seguida, alimenta outros seres permitindo a continuidade da vida.

O segundo princípio, recursivo, “[...] é um processo onde os produtos e os efeitos são ao mesmo tempo causas e produtores do que os produz. Temos um exemplo, do indivíduo, da espécie e da reprodução" (MORIN, 2011a, p. 74). Ensina-se que, numa situação em que existe uma causa "a", será gerado um efeito "b". A recursividade, porém, gera um efeito que produzirá uma causa a qual, por sua vez, gerará um novo efeito. Desta forma, assim como o ser humano é fruto da união biológica de um homem e uma mulher, também será gerador de outras uniões. Para o autor, a própria vida representa esse processo de recursividade que se autorregula, já que "nossas vidas dependem desse processo permanente de regeneração (a respiração conduz o oxigênio que o coração veicula pelo sangue nas células que ele desintoxica incessantemente)" (MORIN, 2015, p. 113). Portanto, o princípio da recursividade busca promover o diálogo com o novo, transformando o diálogo em novas estruturas cognitivas do pensamento e da realidade.

O terceiro princípio é o hologramático: o todo está na parte que está no todo, como o próprio ser humano, que é um indivíduo - a parte -, contém dentro de si a sociedade, uma vez que reflete a cultura, a linguagem e as normas sociais, com reflexos no mundo biológico e no sociológico, como indica Morin (2011a). O autor exemplifica a totalidade como o princípio hologramático, que "quase a totalidade do patrimônio genético está presente em cada célula do ser vivo" (MORIN, 2015, p. 22). Esta visão da globalidade e da totalidade harmoniza-se

\begin{tabular}{l|l|l|l|ll|l} 
(C) Revista Triangulo & Uberaba, Minas Gerais & v. 11 & n.3 & p. $159-178$ Set. / Dez. & 2018
\end{tabular}


bem com o princípio hologramático porque "cada célula contém a totalidade do patrimônio genético de um organismo policelular; a sociedade, como um todo, está presente em cada indivíduo, na sua linguagem, em seu saber, em suas obrigações e em suas normas" (MORIN, 2000, p. 35). Deste modo, as células do organismo são um exemplo de totalidade: o DNA contém todas as informações do todo e a própria célula é a parte. Cada célula comporta a totalidade do patrimônio genético de um organismo policelular. Assim, a sociedade, como um todo, está presente em cada indivíduo, na sua linguagem, em seu saber, em suas obrigações e em suas normas. Portanto, o pensamento hologramático gera para o ser humano a capacidade de visualizar o objeto em três dimensões simultaneamente, dado que o todo completa as partes e as partes completam o todo, pensamento que se manifesta tanto no mundo biológico como no sociológico, já que "o sociólogo é uma parte desta sociedade. O fato de ser detentor de uma cultura sociológica não o coloca no centro da sociedade. Ao contrário, ele faz parte de uma cultura periférica na universidade e nas ciências" (MORIN, 2011a, p. 75). Esta trama complexa liga a ideia hologramática à recursiva, que está vinculada, em parte, à dialógica.

Para melhor compreender os três princípios do Pensamento Complexo, convém distingui-lo do Pensamento simplificador e reducionista da ciência clássica ${ }^{\text {iii }}$, conforme representado abaixo:

Figura 1 - Diagrama dos princípios Cognitivos do Pensamento Complexo Proposto por Morin

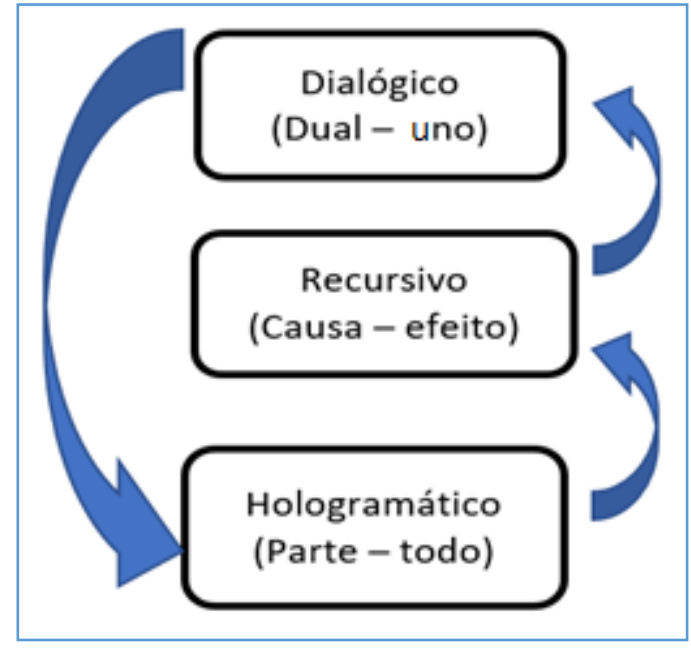

Fonte: elaborado pelos autores, 2018

Os operadores cognitivos do Pensamento Complexo permitem compreender as relações de entrelaçamento de uma determinada situação na grande urdidura da tessitura. A própria vida é uma grande urdidura de relações que se trança até formar uma vasta rede de conhecimentos interconectados na sua totalidade. Quanto mais conexões são estabelecidas, 
mais complexos tornam-se a vida e o pensamento, mais ricas as relações e a comunicação, o que leva a um mundo próspero no sentido coletivo e humanístico.

1.2 Entrelaçando Leituras das Diretrizes Curriculares Nacionais do Curso de Pedagogia Apoiadas no Pensamento Complexo

As DCNs do curso de Pedagogia significam um processo, representam um novo olhar sobre a docência, visto serem a materialização histórica de embates e conquistas na área da educação. Repetindo o mote - em que insistia Morin - de que a ciência traz liberdade e não alienação, cumpre dizer que as DCNs do curso de Pedagogia foram e continuam sendo um grande passo de reflexão para formar profissionais da educação. A direção desses passos conduz a um olhar novo - não singular -, mas simultâneo e plural sobre o mundo contemporâneo, posto que a complexidade que vivemos "está no coração da relação entre o simples e o complexo, porque uma tal relação é ao mesmo tempo antagônica e complementar" (MORIN, 2011a, p. 103) como as próprias DCNs do curso de Pedagogia em sua ação concreta sobre o curso, que é paradigmático ${ }^{\text {iv }}$, representando a um só tempo para os futuros pedagogos antagonismo e complementaridade.

As próprias DCNs propõem abordagens teóricas e práticas à docência, indo além da visão educacional, envolvendo aspectos do ensino, gestão e pesquisa, apresentados nos art. $1 .^{\circ}$ e $2 .^{\circ}$ e reafirmados no art. $4 .^{\circ}$. O art. $1 .^{\circ}$ aponta uma direção para as instituições de Ensino Superior, sobre a formação da educação e do futuro pedagogo, e o art. $2 .^{\circ}$ expõe o campo das finalidades profissionais - formação e atuação do futuro pedagogo -, funções amplas e abrangentes que em muito ultrapassam a docência. Deste modo, o art. $4 .^{\circ}$ retoma os argumentos dos artigos anteriores, mas reafirma os campos de atuação do futuro Pedagogo e dá à docência o papel de grande eixo norteador da ação educativa nos diversos campos da educação.

Analisando os art. $1 .^{\circ}, 2 .^{\circ}$ e $4 .^{\circ}$ das DCNs do curso de Pedagogia, é conveniente relacioná-los com o operador cognitivo dialógico. Como se pode observar na Figura 2. 
Figura 2 - Art. $1^{\circ}, 2^{\circ}$ e $4^{\circ}$ das DCNs do Curso de Pedagogia com entrelaçamentos do Pensamento Complexo dialógico de Edgar Morin

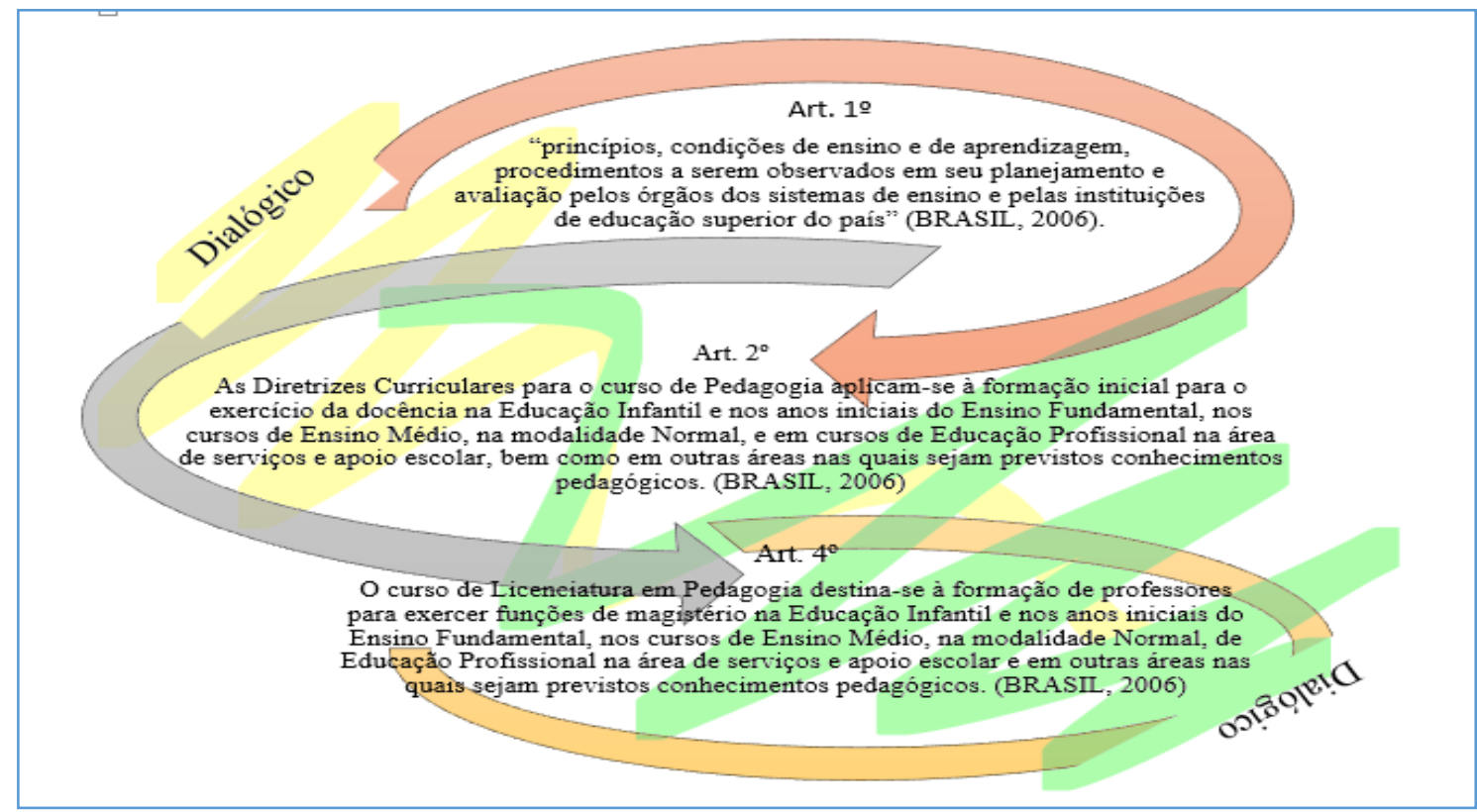

Fonte: elaborado pelos autores, 2018.

A Figura 2 apresenta o operador dialógico, demonstrando a possibilidade de aproximação do processo formativo, que é aparentemente antagônico, ao passo que são artigos independentes, mas apontam o olhar de complementaridade. O dialógico é composto das inter-retroações constantes - entre o mundo biológico, físico e social - que representa a própria docência no sentido de dualidades, dúvidas e conflitos, mas articulam-se de forma simultânea ao longo do processo formativo dos futuros pedagogos.

Quanto ao art. 5. ${ }^{\circ}$, está vinculado aos egressos do curso de Pedagogia e é composto por dezesseis incisos que explicitam as aptidões dos futuros pedagogos, incisos que convém analisar em blocos para otimizar a apresentação do estudo. O primeiro bloco abarca os incisos $\mathrm{V}$, IX e X, que apontam para uma visão e compreensão do futuro pedagogo no que tange às ideias de inclusão de todos e respeito, aspectos socioculturais no território da diversidade social, religiosa, ambiental-ecológica, étnico-racial e de gênero. Estes incisos podem ser relacionados ao pensamento de recursividade que "traduz a capacidade de um sistema para manter-se em equilíbrio diante das variações do meio" (MARIOTTI, 2010, p. 141). Partindo deste pensamento de Mariotti, elaborou-se a Figura 3. 

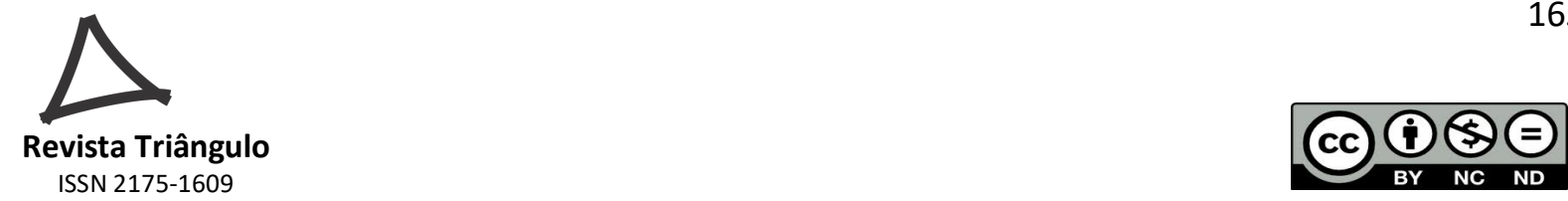

Figura 3 - Primeiro Bloco - art. $5^{\circ}$ nos incisos I, V, IX e X das DCNs do curso de pedagogia com entrelaçamentos do Pensamento Complexo de Recursividade de Edgar Morin

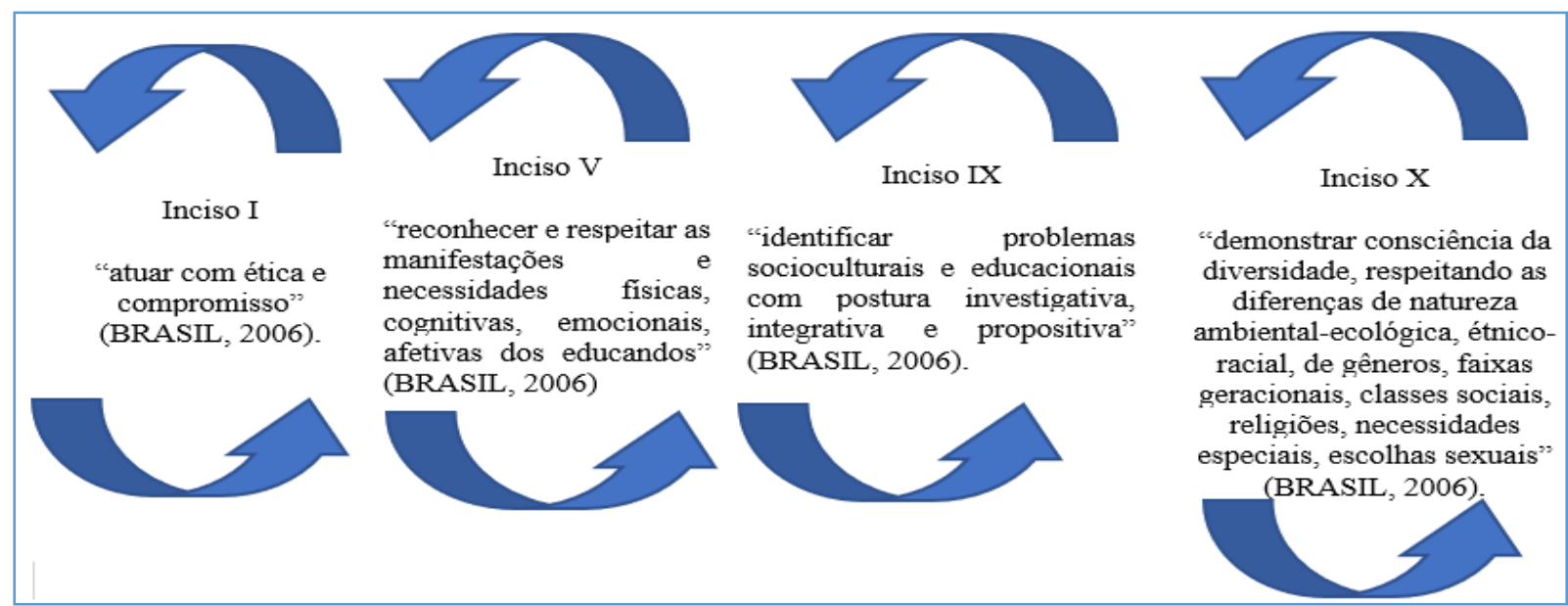

Fonte: elaborado pelos autores, 2018.

Nota-se a multiplicidade de setas representando a ideia de recursividade. A multiplicidade de uma relação de metalinguagem é a representação que colabora com a reflexão de que o futuro egresso de Pedagogia na sua atuação profissional vê-se em situações em que é preciso retomar a própria prática. Este processo faz circular o efeito sobre a causa, não de forma linear, mas vivencial, ao longo do processo, ações que religam o que há muito tempo vem sendo segmentado, compartimentalizado ou separado; ou seja, "os produtos e efeitos gerados por um processo recursivo são, ao mesmo tempo, cocausadores desse processo" (MORIN, 2011b, p. 103). Convém observar ainda os verbos no infinitivo de cada inciso relacionados à ideia de circularidade: "I - atuar [...], V- reconhecer [...], IX - identificar [...] e X - demonstrar" (BRASIL, 2006), verbos que sugerem interpretação no operador cognitivo recursivo, à medida que os egressos vão revendo, se ajustando ou construindo ao longo de suas práticas novos processos de formação e autoformação. Todo esse contexto de recursividade possibilita ao egresso inferir o processo de criação e desequilíbrio, de conflitos cognitivos, do reconhecimento e da ativação dos conhecimentos prévios que fazem circular o efeito sobre a causa.

O segundo Bloco do art. $5 .^{\circ}$ - incisos II, III, VI e VII - faz referências aos conteúdos e às modalidades da educação. Os incisos argumentam sobre o cenário dos processos educativos no desenvolvimento humano desde a educação infantil até o fundamental. Portanto, o futuro pedagogo pode utilizar/desenvolver as várias linguagens presentes no mundo contemporâneo e conhecimentos tecnológicos. Necessitará de uma formação inicial 
que ofereça, na sua matriz curricular, as ementas e disciplinas que contemplem conhecimentos tecnológicos, no sentido de aplicabilidade pedagógica e operacional, inferindo o ensino e a aprendizagem. Este bloco enseja analisar a importância da ideia do desenvolvimento humano, representado visualmente na Figura 4.

Figura 4 - Segundo Bloco do art. 5, incisos II, III, VI e VII, das DCNs do Curso de Pedagogia com entrelaçamentos do Pensamento Complexo hologramático de Edgar Morin

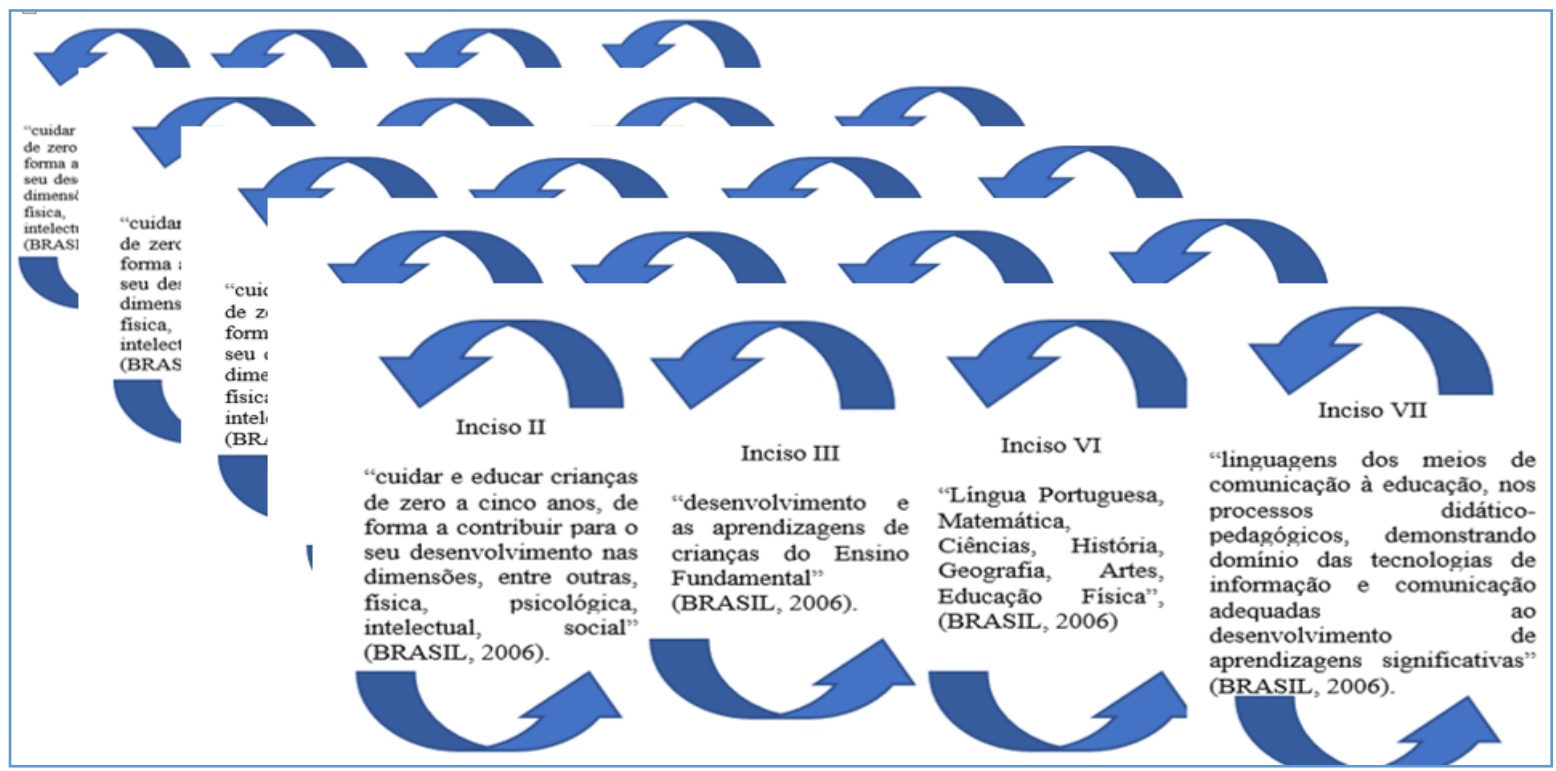

Fonte: elaborado pelos autores, 2018.

A representação hologramática reproduzida na Figura 4 mostra muitas facetas multiplicando-se infinitamente. Os incisos II, III, IV e VII relacionam-se com o operador cognitivo hologramático do Pensamento Complexo de Morin. O homem faz parte de um sistema complexo que é tecido em seus conjuntos. O desenvolvimento humano compõe-se de etapas - biológicas, afetivas e sociais - formando um todo que não admite separação. $\mathrm{O}$ futuro educador lidará com a relação de não separar o objeto do ser, mas compreenderá suas relações do desenvolvimento cognitivo do educando e trabalhará com o conhecimento de forma significativa.

O terceiro bloco do art. 5. ${ }^{\circ}$ abrange os incisos VIII, XII, XIII. O inciso VIII aborda os desafios que o futuro pedagogo deve estabelecer nas relações entre o aluno e a comunidade escolar. A instituição escolar exerce um papel importante nas relações entre a família e a comunidade. Segundo o pensamento complexo, essa relação permite "viver por meio das próprias experiências, primeiro com a ajuda dos pais, depois dos professores, mas também por meio dos livros, da poesia, dos encontros" (MORIN, 2015, p. 15). É o que está representado na Figura 5. 
Figura 5 - Terceiro Bloco do art. $5^{\circ}$, inciso VIII, das DCNs do Curso de Pedagogia com entrelaçamentos do Pensamento Complexo Hologramático de Edgar Morin

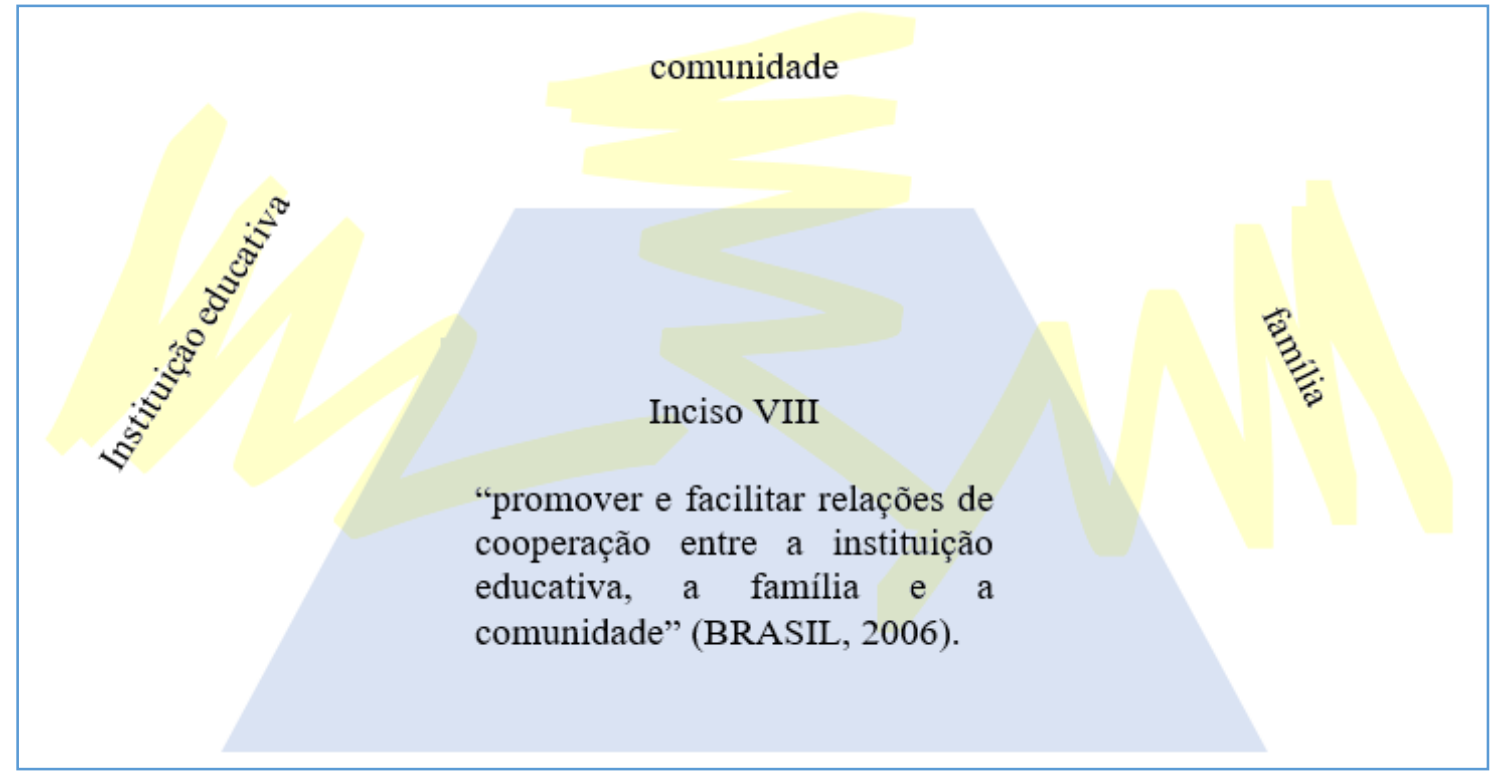

Fonte: elaborado pelos autores, 2018.

O inciso VIII do art. 5. ${ }^{\circ}$ das DCNs do Curso de Pedagogia, no contexto do operador hologramático, representa o todo e as partes refletidas nas próprias DCNs. Este princípio de pura instabilidade reflete tanto o que vivencia o egresso do curso de Pedagogia durante sua formação quanto o profissional, porque "o próprio todo está, de certa maneira, presente na parte que se encontra nele" (MORIN, 2011b, p. 102). O inciso VIII apresenta aspectos da sociedade: instituição escolar, família e a comunidade, que, por sua vez, se refletem na cultura, porque "[...] a sociedade e a cultura estão presentes enquanto todo [...]" (MORIN, 2011 b, p. 102). O papel do egresso de Pedagogia que o inciso propõe olhado à luz do pensamento complexo é "promover", "facilitar relações" e "cooperação" (BRASIL, 2006), mas, em uma perspectiva de holograma, que fragmenta a imagem do próprio ser em outras imagens duplicadas, aflora o princípio cognitivo hologramático com o qual o egresso terá de aprender a entrelaçar com as concepções de seu cotidiano, cuidando para não dissociar as partes do todo.

Além disso, os incisos XII e XIII abrem a possibilidade de o futuro pedagogo desenvolver um trabalho em equipe e manter diálogo. Constata-se, aqui, a importância do processo avaliativo, uma vez que a participação do professor permite contribuir na implementação e no acompanhamento, executando e avaliando tanto na gestão como em projetos educacionais formais e não formais, como mostra a Figura 6. 
Figura 6 - Terceiro Bloco do art. 5. ${ }^{\circ}$, incisos XII e XIII, das DCNs do Curso de Pedagogia com entrelaçamentos do Pensamento Complexo de Edgar Morin.

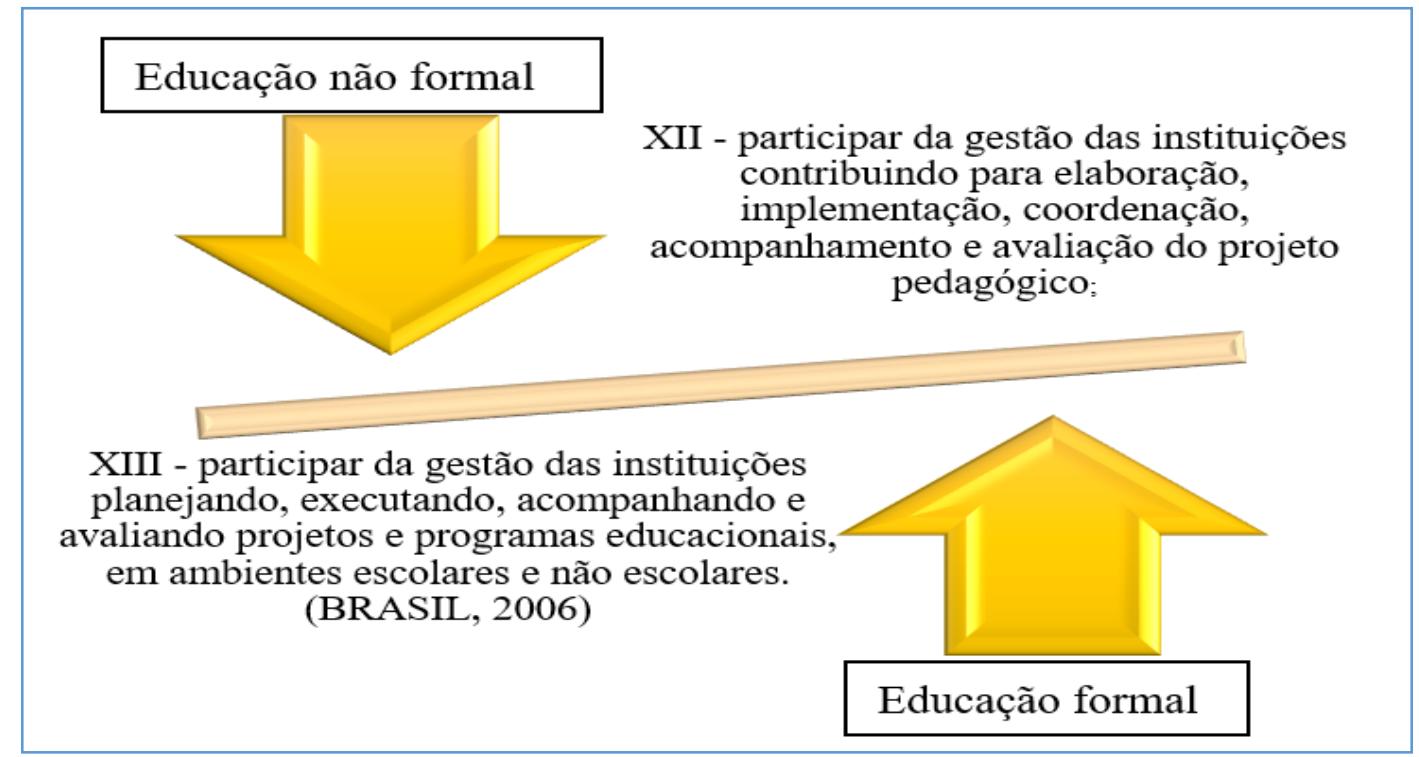

Fonte: elaborado pelos autores, 2018.

Compreende-se, à luz do pensamento complexo, que o professor está em condições de perceber "as relações mútuas e as influências recíprocas entre parte e todo em um mundo complexo" (MORIN, 2015, p. 101). Assim, participar do processo avaliativo torna possível compreender as relações do todo e das partes nas situações da instituição escolar.

$\mathrm{O}$ quarto e último bloco selecionado do art. 5. ${ }^{\circ}$ examina o inciso XIV, o qual exalta a importância do futuro pedagogo no ensino e aprendizado ao construir ou proporcionar conhecimentos sobre os "alunos e alunas e a realidade sociocultural em que estes desenvolvem suas experiências não escolares; sobre processos de ensinar e de aprender" (BRASIL, 2006). Ademais, abre-se, aos futuros pedagogos, a possibilidade de atuar em trabalhos e práticas educativas em ambientes como organizações não governamentais. $\mathrm{O}$ inciso XV complementa o inciso anterior porque permite ao futuro pedagogo "utilizar, com propriedade, instrumentos próprios para a construção de conhecimentos pedagógicos e científicos" (BRASIL, 2006). A expectativa é que "estes profissionais desenvolvam uma visão integradora, buscando articular e religar os conhecimentos, bem como contextualizar os processos de produção dos conhecimentos" (SANTOS, SUANNO e SUANNO, 2013, p. 45). Depreende-se que os incisos XIV e XV podem ser relacionados com o operador cognitivo sujeito-objeto, porque o futuro pedagogo faz parte daquilo que observa. O sujeito observador - não está separado do objeto - observado -, dependendo, por isso, o processo de ensino e aprendizado da atuação do professor em articular mecanismos com a realidade dos 
alunos e com os conhecimentos, não apenas criando uma relação entre professor, aluno e objeto, mas religando os conhecimentos entre observador e o observado de forma integradora.

Quanto à estrutura do curso de Pedagogia, o art. 6. ${ }^{\circ}$ das DCNs apresenta três núcleos: um sobre estudos básicos; outro sobre aprofundamento e diversificação de estudos; e um terceiro sobre estudos integradores. Os três núcleos permitem a cada Instituição de Ensino Superior (IES) construir o seu Projeto Pedagógico (PP) de acordo com suas condições institucionais e regionais. Deste modo, o art. $6 .^{\circ}$ estimula cada instituição a ponderar as possibilidades e oportunidades em construir a própria matriz curricular. À luz do pensamento complexo de Morin, portanto, pode-se argumentar que os núcleos de estudos básicos, de aprofundamento e integradores são possibilidades para lidar com os saberes científicos da universidade, já que é "paradoxal a dupla função da Universidade: adaptar-se à modernidade científica e integrá-la; responder às necessidades fundamentais de formação, mas, também, e sobretudo, fornecer um ensino metaprofissional, metatécnico, isto é, uma cultura" (MORIN, 2010, p. 82).

O inciso I do art. $6^{\circ}$, que trata do núcleo de estudos básicos, discorre sobre a diversidade e a multiculturalidade da sociedade brasileira no sentido da reflexão e ações críticas. Sob a perspectiva de Morin, toda reflexão e ação crítica deve reverter na formação do pedagogo-professor e ensina-lhe que manejar o ensinar e o aprender "é exatamente isso: saber se distanciar, saber se objetivar, saber se aceitar, saber meditar, refletir" (MORIN, 2015, p. 39). As dez alíneas do núcleo de estudos básicos possibilitam desenvolver neste futuro pedagogo toda a fundamentação teórica básica.

O inciso II do art. 6. ${ }^{\circ}$ expõe o núcleo de aprofundamento e diversificação de Estudo, que é o estudo voltado às áreas de atuação profissional, atrelado ao projeto pedagógico da instituição, e visa atender às diferentes demandas sociais. Este núcleo corresponde à prática pedagógica, articulando disciplinas com perspectiva das realidades sociais refletidas em vários campos da educação. Cabe à própria Instituição de Educação Superior produzir e se organizar, o que remete ao operador cognitivo da recursividade, que "constitui um circuito em que os efeitos retroagem sobre as causas, sendo os próprios produtos produtores do que os produz" (MORIN, 2012, p. 299).

O inciso III do art. $6 .^{\circ}$, por sua vez, apresenta o núcleo de estudos integradores, cuja finalidade é enriquecer o currículo. O núcleo permite que a IES promova uma ação pedagógica e integrada nos múltiplos olhares diferenciados para dar conta dos diversos conhecimentos plurais e distintos dos fenômenos. A ideia de integrar os núcleos materializa-

\begin{tabular}{l|l|l|l|ll|l} 
(C) Revista Triangulo & Uberaba, Minas Gerais & v. 11 & n.3 & p. $159-178$ Set. / Dez. & 2018
\end{tabular}


se nas alíneas, que permitem "um pensamento capaz de não se fechar no local e no particular, mas de conceber os conjuntos, estaria apto a favorecer o senso da responsabilidade e da cidadania" (MORIN, 2010, p. 97). Portanto, o núcleo de estudos integradores possibilita à integração ir além do campo particular e de aperfeiçoamento profissional. Assim, relacionando-os com o princípio do pensamento complexo, compreendemos que os egressos podem assumir a responsabilidade de "aprender de forma permanente, de educar-se, aperfeiçoar-se ou transformar-se pessoalmente ao mesmo tempo em que ajudam e se responsabilizam pela educação e pela transformação dos demais" (MORAES, 2015, p. 132).

A Figura 7 pretende deixar mais clara a função dos operadores cognitivos de Edgar Morin.

Figura 7 - Diagrama sobre os Princípios Cognitivos do Pensamento Complexo propostos por Morin entrelaçados com o art. $6 .^{\circ}\left(1 .^{\circ}, 2 .^{\circ}\right.$ e $3 .^{\circ}$ núcleos):

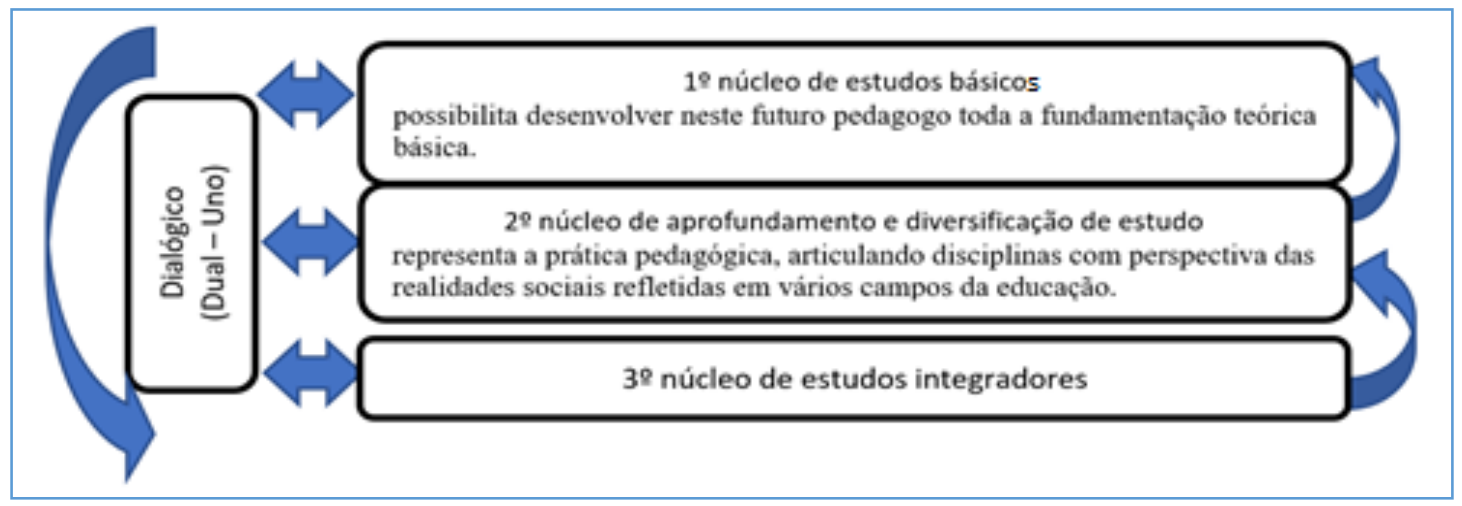

Fonte: elaborado pelos autores, 2018.

Relaciona-se na Figura 7 o operador cognitivo dialógico do pensamento complexo com os núcleos básicos, de aprofundamento e integradores porque, apesar de fragmentados e muitas vezes comportarem contradições de como implantar o curso de Pedagogia ou de como aplicá-los no processo de formação dos futuros pedagogos, há que considerar a importância de lidar com o "antagonismo e ultrapassar os paradoxos [uma vez que] lá é que está a complexidade" (MARIOTTI, 2010, p. 151). O operador dialógico está relacionado com o dual e o uno, por exemplo, e pode estruturar um currículo que desenvolva conhecimentos e olhares no processo de formação, sobre o desenvolvimento econômico da comunidade escolar, mas, ao mesmo tempo, precisa estar sintonizado com os aspectos ambientais em um contexto sustentável. O que se procura é a integração social, harmonizando as diversidades e mantendo suas próprias características, individualidades e aspectos culturais.

Prosseguindo na análise das DCNs na Resolução n. ${ }^{\circ} 1$ do CNE/CP 2006, constata-se que o art. $7 .^{\circ}$ preconiza: 
o curso de Licenciatura em Pedagogia terá a carga horária mínima de 3.200 horas de efetivo trabalho acadêmico, assim distribuídas: I 2.800 horas dedicadas às atividades formativas como assistência a aulas, realização de seminários, participação na realização de pesquisas, consultas a bibliotecas e centros de documentação, visitas a instituições educacionais e culturais, atividades práticas de diferente natureza, participação em grupos cooperativos de estudos; II - 300 horas dedicadas ao Estágio Supervisionado prioritariamente em Educação Infantil e nos anos iniciais do Ensino Fundamental, contemplando também outras áreas específicas, se for o caso, conforme o projeto pedagógico da instituição; III - 100 horas de atividades teórico-práticas de aprofundamento em áreas específicas de interesse dos alunos, por meio da iniciação científica, da extensão e da monitoria (BRASIL, 2006).

Estabelece-se, assim, na esfera do pensamento complexo, a importância do estágio, porque ele permite emergir "da ação e da interação dos participantes com a realidade" (MORAES, 2012, p. 100). A ação e interação no processo do estágio permitem ao estudante de Pedagogia compreender as realidades estudadas no decorrer do curso e refletir sobre elas.

À vista disso, o operador cognitivo que entrelaça o art. 7. ${ }^{\circ}$ é a interação sujeito-objeto, sendo o estágio o elo no qual o estudante faz parte do que observa. Portanto, se houver interesse em "perceber o real com um mínimo de confiabilidade, é importante, antes de examinar uma situação ou tentar resolver um problema, verificar nossas pretensas 'certezas' em relação ao que pretendemos apreciar" (MARIOTTI, 2010, p. 160). Desse modo, o estágio proporciona atos reflexivos sobre as certezas construídas como sujeitos e o objeto educacional.

As DCNs do curso de Pedagogia permitem uma construção de saberes pertinentes ao projeto pedagógico do curso. Sendo elas o alicerce, são de extrema importância para a constituição deste projeto, uma vez que a educação é um processo transcendental no que tange à responsabilidade dos próprios estudantes, educadores, família e a comunidade. Desta maneira, o projeto pedagógico da instituição passa a organizar, a incrementar mecanismos que permitem aos futuros pedagogos uma formação integrada às diferentes estruturas do conhecimento articuladas em um todo.

1.3 Projeto Pedagógico de Curso e o Currículo nas Diretrizes Curriculares Nacionais do Curso de Pedagogia

O Projeto Pedagógico (PP) é um grande desafio da Instituição de Educação Superior, visto que "não se constitui na simples produção de um documento, mas na consolidação de 
um processo de ação - reflexão - ação que exige o esforço conjunto e a vontade política do coletivo escolar" (VEIGA, 2012, p. 56). Assim, longe de pretender engessar todo o processo, o Projeto Pedagógico apresenta-se como

\begin{abstract}
um meio de engajamento coletivo para: a) integrar ações dispersas de ensino, pesquisa e extensão; b) criar sinergias no sentido de buscar soluções alternativas para diferentes momentos do trabalho acadêmico-administrativo; c) desenvolver o sentido de pertença; d) mobilizar os protagonistas para a explicitação de objetivos comuns, definindo o norte das ações a serem desencadeadas; e) fortalecer a construção de uma coerência comum, mas indispensável, para que a ação coletiva produza seus efeitos (VEIGA, 2004, p. 54).
\end{abstract}

Todo o processo de engajamento, de reflexão, de construção colaborativa com desenvolvimento constante de pertencimento deve ocorrer de forma globalizada na IES. Entretanto, qual a funcionalidade do Projeto Pedagógico? Ele funciona com um conjunto de elementos para traçar o perfil dos alunos, analisar o contexto sociocultural da comunidade em que está inserido e dos profissionais atuantes na IES, constituindo-se num rumo, numa rota compartilhada no processo das ações dos professores. Servimo-nos das argumentações de Veiga (2004, p. 16) para compreender a finalidade do PP, caracterizado como "instrumento de ação política [que] deve estar sintonizado com uma nova visão de mundo, expressa no paradigma emergente de ciência e de educação, a fim de garantir uma formação global [...]”.

Ao permitir problematizações e a possibilidade de reconfigurações quanto ao cotidiano e à dinâmica institucional, o Projeto Pedagógico torna-se peça fundamental no processo de construção e planejamento dessa mesma Instituição.

Muitas vezes é caracterizado como processo de projeção futurística e de ações sistematizadas, resumido em "projetar é lançar-se para o futuro. É um instrumento que visa orientar os desafios do futuro. O futuro não está dado, não é algo pronto. É preciso entender que o projeto é caracterizado como uma ação consciente e organizada" (VEIGA, 2012, p. 57).

O Projeto Pedagógico da Instituição de Educação Superior é abordado no art. $8 .^{\circ}$ das DCNs do curso de Pedagogia, desde o inciso I, que trata das disciplinas, "seminários e atividades de natureza predominantemente teóricas que farão a introdução e o aprofundamento de estudos, entre outros, sobre teorias educacionais, situando processos de aprender e ensinar historicamente" (BRASIL, 2006). Este inciso explicita o valor teórico no processo de ensino e aprendizagem, valor que servirá de alicerce para estudos mais profundos, dando relevo a todo o processo histórico que reflete as concepções e teorias no presente. Poderá, assim, o futuro pedagogo compreender as relações das ações da prática com os conhecimentos disciplinares e das atividades desenvolvidas ao longo do curso de Pedagogia.

\begin{tabular}{l|l|l|l|ll|l} 
(C) Revista Triangulo & Uberaba, Minas Gerais & v. 11 & n.3 & p. $159-178$ Set. / Dez. & 2018
\end{tabular}


Castro (2007) esclarece que o art. $8^{\circ}$ carrega aspectos dinâmicos que podem ser implementados pelas IES nos Projetos Pedagógicos, em que deverão ser propostas as práticas "previstas nas Diretrizes Curriculares do curso. Consideramos interessante a proposta de participação de todos os professores nas atividades práticas, mediante a elaboração de um projeto de prática, envolvendo todos" (CASTRO, 2007, p. 222). Cabe ainda assinalar que o trabalho de conclusão de curso estabelece a relação entre a formação do profissional da educação e a opção para a área de aprofundamento, como, por exemplo, docência, gestão ou ainda ações diretamente ligadas a alunos de necessidades especiais ou ligadas à educação de jovens e adultos.

Interpretado à luz do pensamento complexo, o Projeto Pedagógico é ferramenta inestimável para articular "os domínios disciplinares em um sistema teórico comum" (MORIN, 2010, p. 112). Sob esse ângulo, o art. $8 .^{\circ}$ propõe que o projeto pedagógico tenha uma articulação e organização disciplinar dentro do sistema teórico de forma comum no sentido de compartilhar os conhecimentos. Sendo assim, o projeto pedagógico refletiria muito além da docência, englobando tudo o que é preciso compreender para viver na contemporaneidade: política, economia, civilização. Começa-se "a perceber a ligação entre cidade-periferias-moradia-atomização-jovens-drogas-imigrados-desempregados, ainda que cada um desses problemas comporte sua especificidade" (MORIN, 2010, p. 172). Para compreender essas mudanças na atualidade, convém discutir o papel da estrutura curricular.

Isto leva a refletir sobre o currículo como uma possibilidade de entrelaçamento dos fios da urdidura, que se materializam a partir das DCNs no curso de Pedagogia. "O currículo é um conceito de uso relativamente recente entre nós, se considerarmos a significação que tem em outros contextos culturais e pedagógicos nos quais conta com uma maior tradição" (SACRISTÁN, 2000, p. 13). A teoria de currículo abarca em seu processo de constituição, extremamente recente, um modo de organização bastante complexo, bem como as diversidades de alternativas pedagógicas em seus contextos culturais e sociais.

É frequente constatar que o currículo está pautado na fragmentação do conhecimento, visto que sua organização se decompõe em várias disciplinas, distribuídas em cargas horárias, ordenadas por semestres e sem relação com a forma como estão dispostas. Daí materializar-se o currículo por vários fatores, que são como arena política de embates, poderes e relações. Fundamentalmente, o currículo, apresenta aos professores e aos alunos, é uma opção historicamente configurada que se sedimentou dentro de uma determinada cultura, 
política, social e escolar; está carregado, portanto, de valores e pressupostos que é preciso decifrar (SACRISTÁN, 2000, p. 17).

Alarga-se o conceito e passa a incluir que "o currículo é lugar, espaço, território. O currículo é relação de poder" (SILVA, 2014, p. 150). É nesta territorialidade sedimentada que o currículo se legitima na sua própria historicidade em um determinado grupo ou na própria instituição de ensino. Diante disso, "o currículo é capitalista. O currículo reproduz culturalmente - as estruturas sociais. O currículo tem um papel decisivo na reprodução da estrutura de classes da sociedade capitalista” (SILVA, 2014, p. 148).

Neste cenário de "ideologia, cultura e poder", nos dizeres de Moreira e Tadeu (2013, p. 28), é fundamental ter claro que o "mundo funciona em rede e que essa dinâmica operacional está presente em todas as dimensões da vida” (MORAES, 2015, p. 17). Parte integrante dessa conjuntura, o currículo é, forçosamente, urdido em uma grande rede, porque “o conhecimento que constitui o currículo está inextricavelmente, centralmente, vitalmente, envolvido naquilo que somos, naquilo que nos tornamos: na nossa identidade, na nossa subjetividade" (SILVA, 2014, p. 15). Nesse âmbito, Zabala enfatiza a importância de ensinar para a complexidade, uma vez que

é preciso construir um currículo que reflita o nível de incerteza presente na vida, no qual é impossível obter sempre uma única resposta válida e verdadeira para os múltiplos problemas que surgem em uma realidade na qual se inter-relacionam múltiplas e diferentes variações e dimensões. Ou seja, uma formação que facilite uma visão mais complexa e crítica do mundo, superadora das limitações próprias de um conhecimento parcelado e fragmentado que, sabemos, é inútil para enfrentar a complexidade dos problemas reais do ser humano. (ZABALA, 2002, p. 58)

O currículo a elaborar, então, precisa ser integrador, globalizante, contextualizado, capaz de enfrentar os problemas surgidos. Para Zabala (2002), poderá significar o livre trânsito do pensamento linear para o pensamento complexo, razão de sobra para organizar e apresentar os conteúdos em uma perspectiva não apenas disciplinar. O autor apresenta dois conceitos no contexto curricular do pensamento complexo: os métodos globalizados e o enfoque globalizador. Os primeiros são "métodos de ensino completos, e o segundo, uma forma e atitude de conceber o ensino e de se aproximar do fato educativo" (ZABALA, 2002, p. 27). Deste modo, através dos métodos globalizados, os alunos movimentam-se para alcançar o conhecimento sobre um tema de seu interesse, para solucionar algum problema social ou natural que lhes é colocado ou ainda para conseguir construir algo, complementa Zabala (2002). 
Relacionando esta questão ao operador cognitivo hologramático do pensamento complexo, entende-se que "não apenas a parte está no todo, como o todo está inscrito na parte” (MORIN, 2010, p. 94). O currículo e o projeto pedagógico são simultaneamente o todo, mas inscrito em partes. O projeto pedagógico é o todo que comporta o currículo, que está inscrito com suas particularidades e fragmentações.

Para Castro, a estrutura curricular do Projeto Pedagógico da IES está atrelada às DCNs do curso de Pedagogia, considerando seus núcleos básicos, de aprofundamento e integradores, já mencionados e analisados no art. $6^{\circ}{ }^{\circ}$ das DCNs, que objetivam a integração curricular. Em sua opinião,

[...] em princípio, os núcleos de aprofundamento não seriam superpostos ao núcleo de estudos básicos da formação do professor. A estrutura curricular deveria prever a formação paralela: ao lado da formação docente, os alunos fariam opção por um núcleo de aprofundamento, que seria oferecido através de oficinas específicas, sendo suas atividades práticas oferecidas desde o primeiro semestre do curso, partindo do conhecimento e observação até a prática efetiva (CASTRO, 2007, p. 224).

Vê, a autora, com bons olhos a integração curricular utilizando os núcleos propostos pelas DCNs de forma paralela com o núcleo de aprofundamento, bem como a relação da teoria e da prática de forma efetiva nas relações entre currículo e o projeto pedagógico da IES. Neste sentido, refletindo à luz do pensamento complexo, vê-se que "todas as disciplinas, tanto das ciências naturais como das ciências humanas, podem ser mobilizadas, hoje, de modo a convergir para a condição humana” (MORIN, 2010, p. 43). Tanto o Projeto Pedagógico da IES quanto o currículo são elementos fundamentais para o desenvolvimento da formação do pedagogo com vistas a promover a condição humana na atual conjuntura, pois o "viver é uma aventura que implica incertezas sempre renovadas, eventualmente com as crises ou catástrofes pessoais e/ou coletivas" (MORIN, 2010, p. 25).

\section{CONSIDERAÇÕES FINAIS}

As Diretrizes Curriculares Nacionais do curso de Pedagogia representam um marco na organização do currículo, uma vez que apontam direções da função do curso e criam um processo de identidade do pedagogo, que passou a ser a docência - base comum nacional, de sua formação. 
Por esse viés, as DCNs especificam o foco da docência e os conhecimentos que oferecem suporte de formação ao pedagogo. Elas apresentam a organização dos conhecimentos teóricos e práticos de forma indissociável e integrada, estabelecendo a relação entre a teoria e a prática.

Se, por um lado, fortaleceu a formação docente na Educação Básica, esse documento, por outro, provocou uma crise de identidade ampliada pela possibilidade de atuação em outras áreas, além da educação formal, gerando um acúmulo de funções. Contudo, na perspectiva do pensamento complexo, o ato educativo é uma responsabilidade pessoal e social, já que as DCNs são forças que permitem refletir, pensar e compreender as realidades, estabelecendo ligações entre objetos, fatos e dados que não têm - à primeira vista - conexão entre si. $\mathrm{O}$ futuro pedagogo torna-se apto a compreender como as coisas podem influenciar umas às outras e como novas ideias podem emergir de certas situações.

As DCNs do curso de Pedagogia, o Projeto Pedagógico e o currículo são elementos que levam a refletir sobre a complexidade. Embora apontem caminhos, esses documentos ainda não bastam para fixar o rumo a seguir na construção do curso de Pedagogia, posto que, mesmo tendo a liberdade de construção, as IES ainda precisam compreender a necessidade de construir seu próprio currículo e seu Projeto Pedagógico. Nesta interseção do que é desejável e alcançável é que o pensamento complexo ganha espaço e significado, porque permite perceber e entender as situações com mais clareza. A contribuição da complexidade, portanto, reside em ser possível e simultaneamente indispensável pensar em termos de conexões, e não em eventos isolados, cujo objetivo consiste em tomar decisões de grande amplitude e de longo prazo nos contextos institucionais.

Como o pensamento complexo é a representação do que é tecido junto em uma grande teia/rede, que abarca o processo de incertezas, a complexidade é composta por múltiplos sistemas complexos e seus elementos, o que não significa que aumenta à medida que crescem os elementos do sistema, mas que pode aumentar - e muito - pela conexão que os elementos, ainda que poucos, estabelecem entre si. Assim, as DCNs possibilitam mediar ações do mundo incerto, complexo e inesperado. Há situações diversificadas e simultâneas, questões que ocorrem no cotidiano da vida, para as quais, muitas vezes, o currículo e o projeto pedagógico precisam propor teorias pedagógicas e práticas educativas - de preferência imbricadas -, tecidas em conjunto com as DCNs, com o projeto pedagógico e com o currículo, tornando as partes, refletindo simultaneamente no todo, uma vez que é preciso pensá-las de forma interligada e mantê-las conectadas de modo sinérgico. 

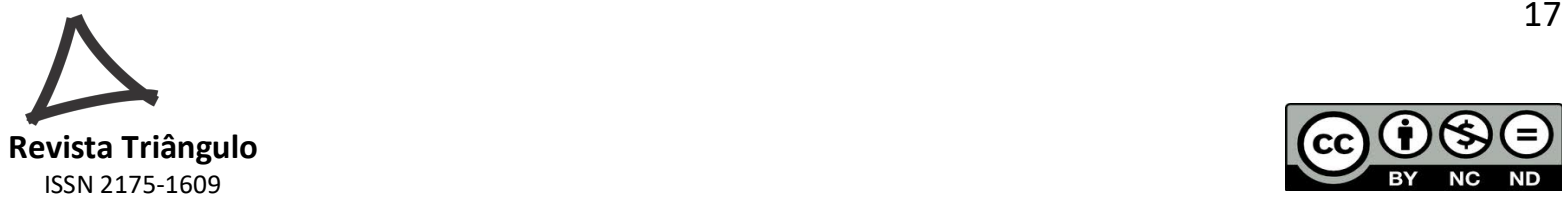

Na perspectiva do pensamento complexo é que uma parte só pode ser definida como tal em relação a um todo, porque um sistema só é concebível quando reflete o seu todo. A riqueza do pensamento complexo é a possibilidade que oferece - uma vez compreendidos seus princípios - a cada instituição de educação superior de pensar em seu próprio contexto (seu ambiente), não reduzindo e padronizando ao espaço ambiental no qual o curso de formação de professores é oferecido nem, tampouco, prendendo-se excessivamente aos limites das proposições legais. O pensamento complexo resulta na complementaridade das ações e intervenções simultâneas, que são todos os fios da trama, costurados e urdidos com as DCNs ao longo da formação e coformação dos futuros pedagogos com projetos globalizados na relação da comunidade educacional e planetária.

Portanto, as DCNs do curso de Pedagogia, Projeto Pedagógico e o currículo favorecem a sinergia entre os conteúdos científicos e os conteúdos da vida humana. Defende-se a ideia de um pensamento complexo no processo de formação de professores, cujo objetivo profissional e humanístico será a luta pela cidadania e pela justiça, permeada pelos conhecimentos significativos nas suas relações antagônicas e complementares, de causa e efeito. Será essa a forma pela qual tais profissionais e professores poderão retroalimentar-se e regular seu desenvolvimento profissional junto ao mundo, atrelando seu trabalho à defesa da dignidade humana na sua globalidade e à luta pelos direitos fundamentais na sociedade.

\section{REFERÊNCIAS}

BARONE, Clayton Marcelo. Tessituras, Urdiduras e Lançadeiras do Curso de Pedagogia: leituras das diretrizes curriculares nacionais e as interpretações dos professores universitários à luz do Pensamento Complexo. Dissertação (Mestrado em Educação) Universidade Cidade de São Paulo, São Paulo, 2017.

BRASIL. Conselho Nacional de Educação. Parecer CNE/CP 5, 13.12.2005. Brasília, 2005. Disponível em: http://portal.mec.gov.br/cne/arquivos/pdf/pcp05 05.pdf

BRASIL. Resolução n. ${ }^{\circ}$ 1, de 15 de maio de 2006. Diário Oficial da União, n. 92, seção 1, p.11- 12, 16 maio 2006.

CASTRO, M. A formação de professores e gestores para os anos iniciais da educação básica: das origens às diretrizes curriculares nacionais. Revista Brasileira de Política e Administração da Educação, v. 23, p. 199-227, maio/ago. 2007. Disponível em: $<$ http://seer.ufrgs.br/index.php/rbpae/article/view/19126>. Acesso em: 20 de abr. 2018 FERREIRA, Aurélio Buarque de Holanda. Mini Aurélio século XXI escolar: o minidicionário da língua portuguesa. 4. ed. rev. ampl. Rio de Janeiro: Nova Fronteira, 2008. MARIOTTI, H. As paixões do ego: complexidade, política e solidariedade. São Paulo/SP: Palas Athena, 2000. 
Pensamento complexo: suas aplicações à liderança, à aprendizagem e ao desenvolvimento sustentável. 2. ed. São Paulo/SP: Atlas, 2010.

MORAES, M. C. O paradigma educacional emergente. 16. ed. Campinas/SP: Papirus, 2012.

Transdisciplinaridade, criatividade e educação: fundamentos ontológicos e epistemológicos. Campinas/SP: Papirus, 2015.

MOREIRA, Antonio Flavio Barbosa; SILVA, Tomaz Tadeu da. Sociologia e Teoria Crítica do Currículo: uma introdução. In: MOREIRA, Antonio Flavio Barbosa; SILVA, Tomaz Tadeu da. (Orgs.). Currículo, cultura e sociedade. São Paulo/SP: Cortez, 2013.

MORIN, E. Os sete saberes necessários à educação do futuro. Brasília/DF: UNESCO, 2000 .

A cabeça bem-feita: repensar a reforma, reformar o pensamento. Rio de Janeiro /RJ: Bertrand Brasil, 2010.

Introdução ao pensamento complexo. Porto Alegre/RS: Sulina, 2011a.

O método 04: as ideias: habitat, vida, costumes, organização. Porto Alegre/RS: Sulina, $2011 b$.

O método 05: a humanidade da humanidade. Porto Alegre/RS: Sulina, 2012.

Ensinar a viver: manifesto para mudar a educação. Porto Alegre/RS: Sulina, 2015.

PETRAGLIA, I. Edgar Morin: a educação e a complexidade do ser e do saber. Petrópolis (RJ): Vozes, 2010.

Pensamento complexo e educação. São Paulo (SP): Editorial, 2013.

SACRISTÁN, J. G. O currículo: uma reflexão sobre a prática. 3. ed. Porto Alegre/RS: Artmed, 2000.

SANTOS, A.; SUANNO, J. H.; SUANNO, V. R. Didática e formação de professores: complexidade e transdisciplinaridade. Porto Alegre (RS): Sulina, 2013. 323 p.

SILVA, Tomaz Tadeu da. Documentos de identidade: uma introdução às teorias do currículo. Belo Horizonte (MG): Autêntica, 2014.

VEIGA, I. P. A. Educação básica: projeto político-pedagógico; educação superior: projeto político-pedagógico. Campinas/SP: Papirus, 2004.

As dimensões do projeto político-pedagógico: Novos desafios para a escola, Campinas/SP: Esforce, 2012.

ZABALA, Antoni. Enfoque globalizador e pensamento complexo: uma proposta para o currículo escolar. Porto Alegre/RS: Artmed, 2002.

\footnotetext{
${ }^{i}$ Diretrizes Curriculares Nacionais do curso de Pedagogia. A Resolução foi fundamentada no Parecer CNE/CP n. ${ }^{\circ}$ 5/2005 e retificada no Parecer $\mathrm{CNE} / \mathrm{CP}$ n. ${ }^{\circ}$ 3/2006. Essa Resolução retifica os pareceres mencionados, reacende o debate e fomenta as reflexões sobre a formação do profissional da educação.

ii O dialógico não deve ser confundido com o pensamento dialético de Hegel.

iii A partir dos séculos XVI e XVII, a ciência vem trabalhado com o método científico, que se assenta na redução da complexidade (pensamento simplificador, reducionista.). A praxe era dividir o todo em partes para compreendê-lo (racionalismo cartesiano), mesmo o pensamento de ordem e de estabilidade (como se o mundo fosse estático e eterno ou equivalesse a uma máquina - determinismo mecanicista).

iv Para Morin, é o conjunto de princípios e regras de instabilidade desenvolvidos pela ciência clássica. A ciência clássica, segundo o autor, é carregada de ordem, determinismo e a eliminação do sujeito, ao passo que a estrutura do pensamento complexo assenta-se nos princípios dialógico, recursivo e hologramático.
} 